\title{
Posterior Urethral Valves Type 1
}

National Cancer Institute

\section{Source}

National Cancer Institute. Posterior Urethral Valves Type 1. NCI Thesaurus. Code

C123210.

A posterior urethral valve extending from the vera montanum towards the distal meatus. 